\title{
Osteoma: A Case Report Based on Image Technology
}

\begin{abstract}
Alile Carmo ${ }^{1 *}$; Ana Carolina Mariz² ; Leandro Santos ${ }^{3}$; Marianna Torres ${ }^{4}$; Raí Santos ${ }^{5}$; Roberto Monteiro ${ }^{6}$ ${ }^{1}$ University Center CIMATEC, Department of Computational Modeling and Industrial Technology; ${ }^{2}$ Ana Carolina Ramos Mariz, Federal University of Bahia, Institute of Health, Dentistry Department, ${ }^{3}$ Leandro Brito Santos, State University of Bahia; ${ }^{4}$ Marianna Torres, Federal University of Bahia, Institute of Health, Dentistry Department; ${ }^{5}$ Rai Faustino Miranda Santos, University Center CIMATEC, Department of Computational Modeling and Industrial Technology; ${ }^{6}$ Roberto Luiz Souza Monteiro, University Center CIMATEC, Department of Computational Modeling and Industrial Technology; Salvador, Bahia, Brazil
\end{abstract}

\begin{abstract}
Osteomas are benign mesenchymal tumors, characterized by proliferation of compact or modularly bone. They are small, slow-growing lesions, usually asymptomatic and detected in young adults. This tumors can affect the paranasal sinuses and are often diagnosed with incidental findings through imaging tests. Osteomas are typically restricted to the craniofacial skeleton and rarely found in other bones. Osteoma of the gnathic bones may be peripheral or endosteal. The osteomas' etiology is controversial and still unknown. It is more frequent in the frontal sinuses, corresponding to $57 \%$ of the paranasal sinuses osteomas, followed by the ethmoidal and maxillary sinuses. Computed Tomography (CT) is the gold standard to assess the location, extent, and aspects of the injury. The objective of this paper is to present a case report of osteoma diagnosed by computed tomography (CT) scan, indicating the importance of the technology of imaging in the medicine diagnostic.
\end{abstract}

Keywords: Osteoma. Paranasal Sinus Osteomas. Frontal Sinus Osteoma. Computed Tomography.

Osteomas of the frontal sinus is uncommon but not rare [1-8]. Recent surveys confirm that the frontal sinus is the most common location of this benign neoplasms [7]. Osteomas are the most common benign tumors that arise in the paranasal sinuses and the nose, with a slow-growing rate, well-circumscribed, indolent lesions that develop predominantly into the frontal sinus $(80 \%$ of the sinus localization) [6-8]. In the beginning, small osteomas are usually asymptomatic $[3,4,6-8]$. The clinical symptoms depend on the location and the size of the tumor [6]. The most common symptom is a frontal headache or facial pain. Osteomas are usually identified accidentally by X-Ray or CT scan images [6]. The cause of frontal sinus osteoma is unknown and speculative. Many theories have been proposed, but it is uncertain [3-8].

From the histological point of view, there are three types of sinus osteomas [2-8]:

1. Eburnated (ivory, compact type) - very dense, with no evidence of Haversian canals;

Received on 20 February 2019; revised 4 March 2019.

Address for correspondence: Dr. Alile Fixina do Carmo. Avenida $60 \mathrm{Dr}^{\circ}$ Antonio Monteiro Street, Apt. \# 502, Zip Code: 41815-130, Salvador, Bahia, Brazil, phone: +55 71 988960093; e-mail: afcarmo76@gmail.com.

J Bioeng. Biotech. Appl. Health 2019;2(2):75-77.

C 2019 by SENAI CIMATEC. All rights reserved.
2. Mature, spongious osteomas - osseous trabecules associated with fibrous tissue and collagen fibers;

3. Mixed types - with both (1 and 2) histological types.

Two main protocols are used in these tumors: 1. Conservatory: if the osteoma is small and asymptomatic, the better perform is to wait and check the progression of the neoplasm; and 2 . Surgical treatment: if the osteoma has rapidgrowth, presence of infections, severe pain, or orbital complications because of the tumor extension, the surgery is the best procedure [6].

A 37-year-old right-handed female was attended in the clinic of diagnostic imaging at Camaçari city (Bahia, Brazil) to evaluate the maxillary sinuses. During the analysis of the sinus X-ray of the face, a clear radiopaque image was found, located near the upper middle contour of the right orbit, ethmoidal sinus and inferior contour of the frontal sinus (Figure 1). The computed tomography (CT) confirmed the osteoma in the region (Figure 2). Based on the patient clinical history, radiographic images, and histopathology of the lesion, the treatment chosen was conservative.

Osteoma can be observed in any age group, being more prevalent in the third and fourth 
Figure 1. The sinus X-ray of the face.

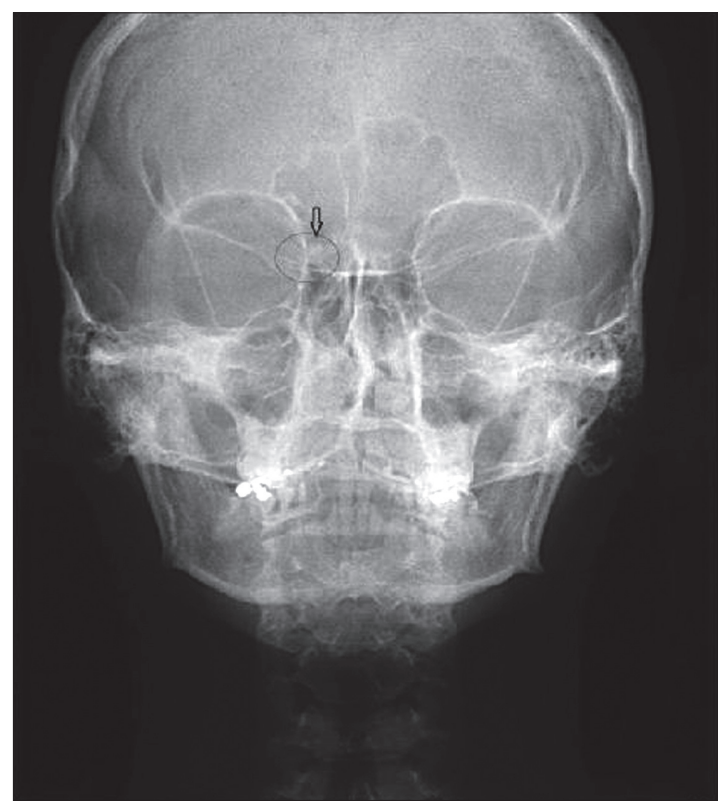

Figure 2. Osteoma visualized on computed tomography (CT).

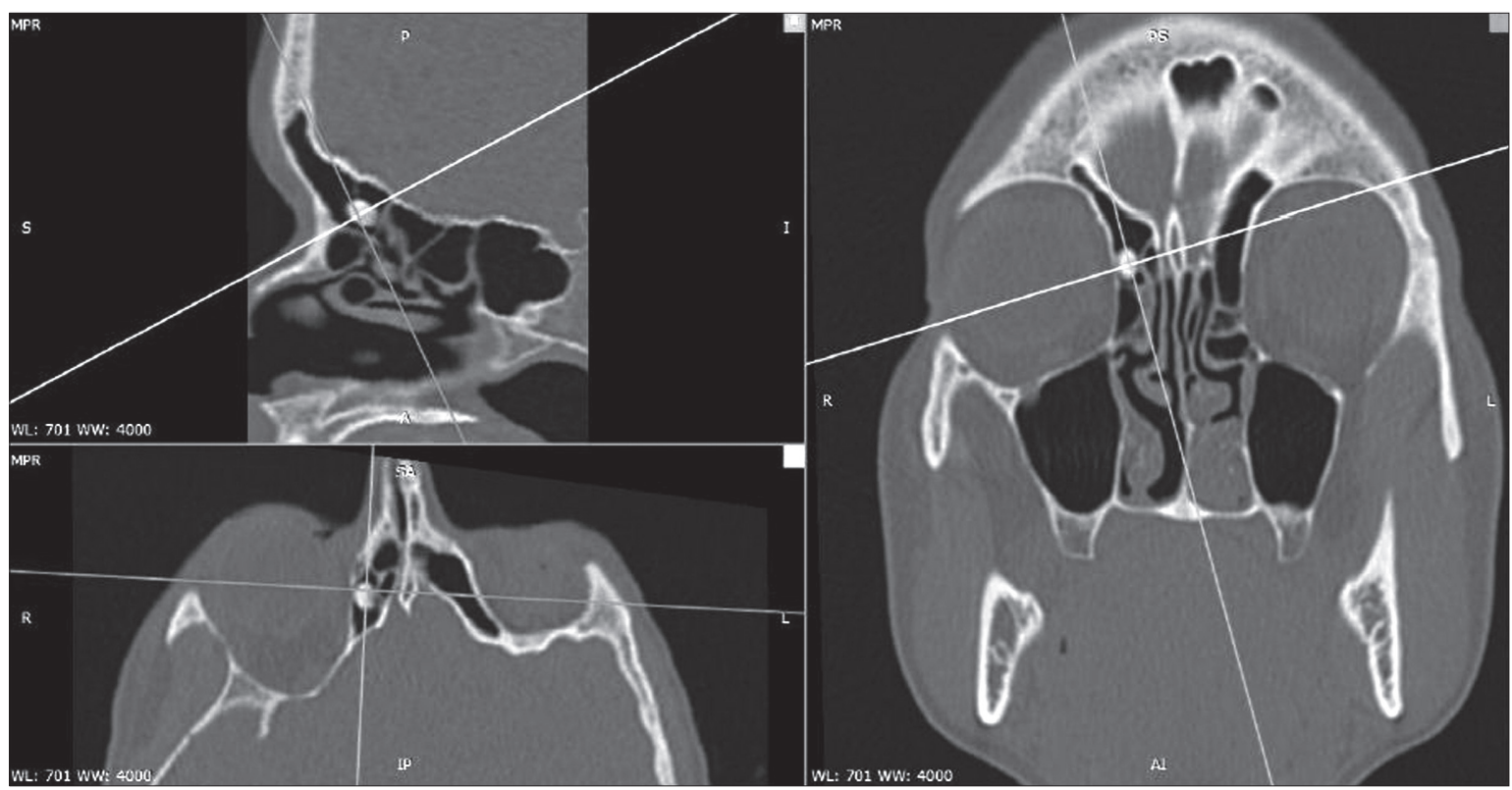

decades of life. The etiology of the osteomas is unknown, in which many theories could be admitted, such as trauma, embryology, infectious diseases, and genetic. Osteomas are benign, indolent, slow-growing tumors of the skull and facial bones, commonly arising around the paranasal sinuses. In about $80 \%$ of cases, they are found solely within the frontal sinus, however the ethmoidal, maxillary, and rarely sphenoid sinuses might be affected as well. The osteoma cannot be considered as the causative agent of the headache, but could be regarded as the complaint that led to 
complementary radiological examination, such as CT.

Diagnosis of osteomas is frequently made incidentally in X-rays, but more especifically with the technology of computed tomography scans. Therefore, the careful evaluation of the radiologist is essential to identify osteomas due to their small size, because they may go unnoticed.

\section{Acknowledgements}

We would like to thank CIMATEC, Federal University of Bahia (UFBA) and CEBRO Clinic for all support in the development of this study.

\section{References}

1. Alsebeith, K.; Desrosiers, M. Bifrontal endoscopic resection of frontal sinus osteoma. The Laryngoscope. 1998;108(2):295-8.
2. Canella, C. Ostenoid osteoma: diagnosis and treatment. Radiologia Brasileira. 2015;48(4):v-v. http://dx.doi. org/10.1590/0100-3984.2015.48.4e1.

3. Fobe, L.P.O; Melo, E.C.; Canone, L.F. Fobe, JL. Cirurgia de osteoma de seio frontal. Arq Neuropsiquiatr, 2002;60(1):101-5.

4. Licci, M. et al. Frontoethmoidal osteoma with secondary intradural mucocele extension causing fronal lobe syndrome and pneumocephalus: Case report and literature review. World Neurosurgery. 2018;115:301-8. https://doi.org/10.1016/j.wneu.2018.04.071.

5. Pons, Y. et al. Ethmoid sinus osteoma: diagnosis and management. Head \& Neck, 2013;35(2):201-4. doi: 10.1002/hed.22945.

6. Sarafoleanu, C; Decusara, R.E. Frontal sinus osteoma. Romanian Journal of Rhinology. 2016;6(22):113-14.

7. Smith, M.E.; Calcaterra, T.C. Frontal sinus osteoma. Annals of Otology, Rhinology \& Laryngology. 1989;98(11):896-900.

8. Summers, L.E. et al. Frontal sinus osteoma associated with cerebral abscess formation: A case report. Surgical Neurology. 2001;55(4):235-9. 